\title{
The accessory soleus muscle causing tibial nerve compression neuropathy: A case report
}

\author{
Dr P Reddy MBChB, HDip Orth(SA), FCOrth(SA)
}

Department of Orthopaedic Surgery, Grey's Hospital, Nelson R Mandela School of Medicine, University of KwaZulu-Natal, Pietermaritzburg, South Africa

Dr GA McCollum MBChB, FCOrth(SA) MMed(UCT)

Department of Orthopaedic Surgery, University of Cape Town, Groote Schuur Hospital, Cape Town, South Africa

\author{
Corresponding author: \\ Dr P Reddy \\ Department of Orthopaedic Surgery \\ Grey's Hospital \\ Nelson R Mandela School of Medicine \\ University of KwaZulu-Natal \\ 3201 Pietermaritzburg, South Africa \\ Tel: +27338973000 \\ Email: Praven.Reddy@kznhealth.gov.za
}

\begin{abstract}
The accessory soleus muscle is a rare anatomic variant which may present as a mass in the posteromedial aspect of the ankle, causing compression of the tibial nerve or an exertional compartment syndrome. It should be considered in the differential diagnosis of all soft tissue masses in this area. Treatment options include conservative treatment, excision of the whole muscle and fasciotomy. We report a case of an accessory soleus in a cyclist presenting with activity-related paraesthesia in the foot and discuss the pathology and management of this condition.
\end{abstract}

Key words: accessory soleus, MRI, tumour, compression neuropathy, fasciotomy

\section{Introduction}

The accessory soleus muscle is an uncommon anatomical variant with a reported incidence of between $0.7-5.5 \% .^{1}$ It may be unilateral or bilateral and although congenital, it is usually asymptomatic and may only present in the second to third decade of life, possibly due to the increased muscle mass and activity during this period. ${ }^{2}$ It may mimic a soft tissue tumour of the lower $\mathrm{leg}^{3}$ and present with painful syndromes of the calf, ankle and foot. ${ }^{4}$

We present a case report of a patient with a unilateral accessory soleus associated with neurological symptoms of his foot.

The accessory soleus muscle is an uncommon anatomical variant with a reported incidence of between $0.7-5.5 \%$

\section{Case report}

A 37-year-old male presented with complaints of intermittent paraesthesia on the plantar aspect of his left foot. He was an avid cyclist and the symptoms only developed during and after a bike ride, typically starting after approximately 20 minutes of riding and was relieved by rest. He reported no occurrence of the symptoms during other activities such as walking or running and had no pain or cramping to suggest an exertional compartment syndrome. He reported that the symptoms began approximately 6-8 months prior to presentation when he began to increase the intensity of his cycling regimen. He had no other symptoms to suggest a pathological origin of the pain. 


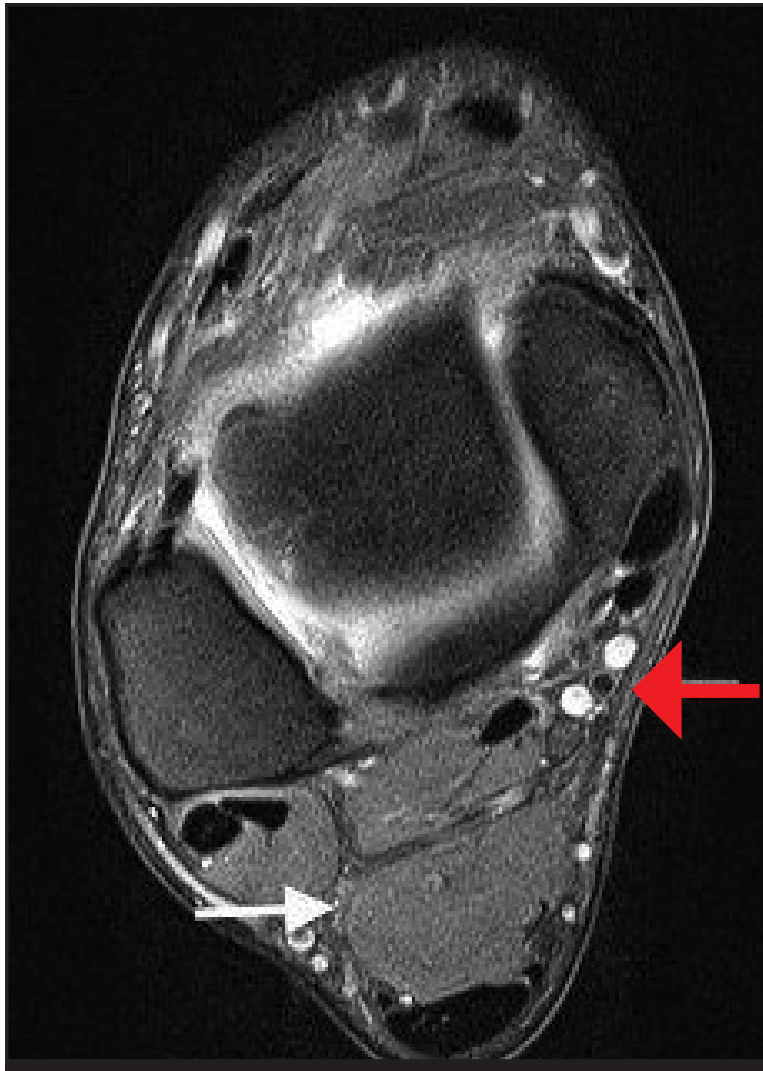

Figure 1. Axial MRI, showing the relationship of the accessory soleus (white arrow) between the deep posterior compartment of the leg and the Achilles tendon and its relationship to the posterior neurovascular structures (red arrow)
Physical examination revealed fullness in the posteromedial aspect of the ankle. He had a normal range of ankle movement, with no features of ankle impingement or instability. There were subtle features of Achilles tendinitis but his Achilles tendon was otherwise normal. He had normal motor and sensory function of the ankle and foot, a negative Tinel test and his symptoms were not reproducible during examination, although the reported paraesthesia was in the typical distribution of the medial and lateral plantar nerves. A contrasted MRI of the foot and ankle was performed, identifying a posterior mass with the same signal intensity as normal muscle in all of the sequences performed. The muscle was located posterior to the deep posterior compartment and anterior to the Achilles tendon in close proximity to the posterior neurovascular bundle (Figure 1), and showed attachment to the posterior tuberosity of the calcaneus (Figure 2). The tibial nerve was flattened and showed intraneural oedema. A small fluid collection was noted around the Achilles tendon suggestive of subtle inflammatory changes. The above findings confirmed the diagnosis of an accessory soleus muscle, and the patient's symptoms were attributed to being caused by a compression neuropathy rather than an exertional compartment syndrome.

A conservative management plan was initially pursued, which included avoidance of cycling for a period of 6 weeks. However, being an enthusiastic cyclist, the patient was not accepting of this course of treatment and the decision was then made to proceed to surgical excision of the accessory soleus muscle.

Findings confirmed the diagnosis of an accessory soleus muscle, and the patient's symptoms were attributed to being caused by a compression neuropathy rather than an exertional compartment syndrome

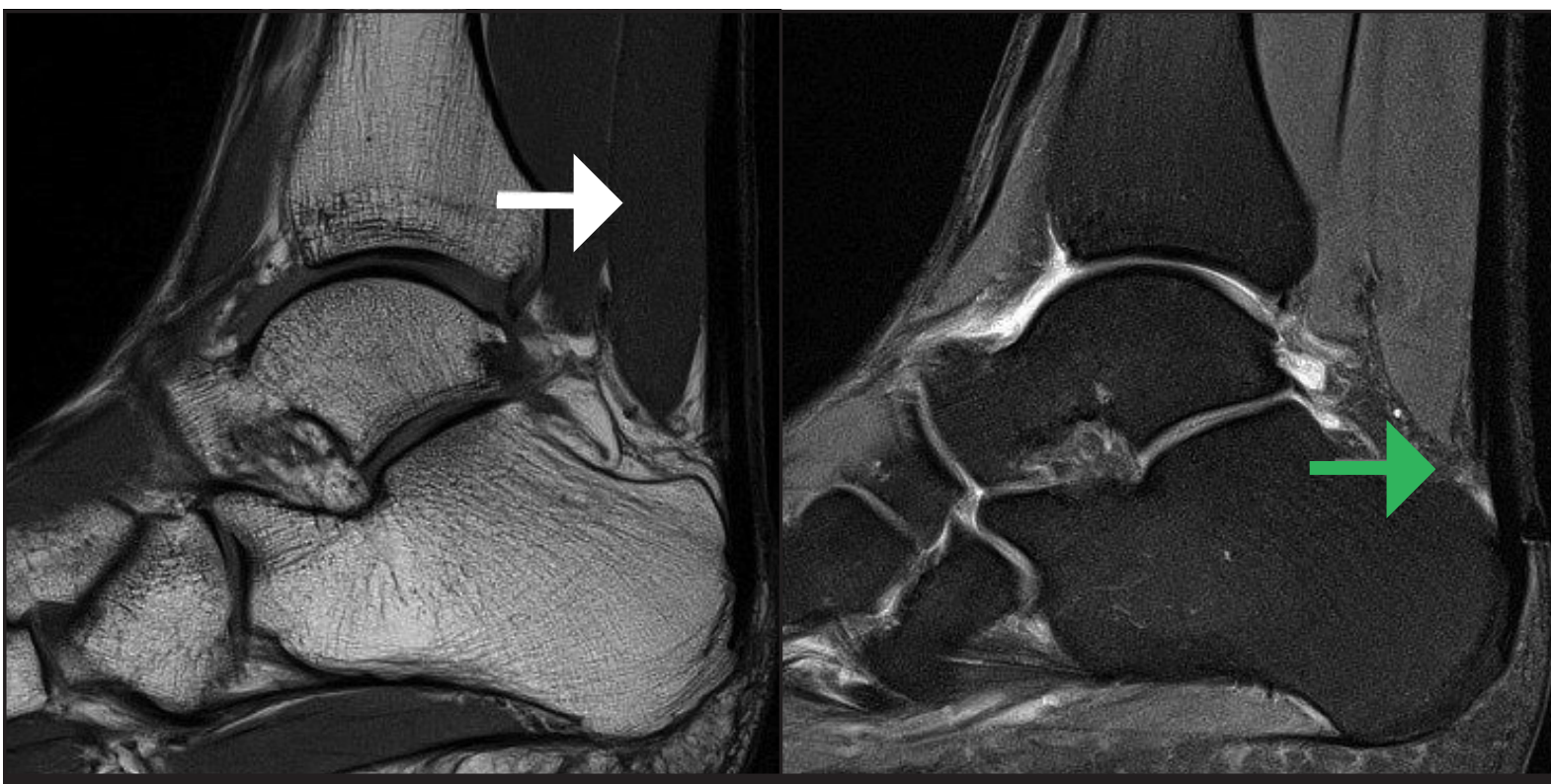

Figure 2. Sagittal MRI, T1 and T2 weighted images showing the accessory soleus (white arrow) having the same signal intensity as normal muscle and its attachment to the calcaneus (green arrow) 
Under a general anaesthetic with the use of a tourniquet, the muscle was approached through a longitudinal incision posteromedial to the distal tibia and ankle. The accessory soleus was noted to be enclosed in its own fascial sheath (Figure $3 a$ ) with attachment to the calcaneus via a micro tendon (Figure 3b). It was closely apposed to the tibial nerve which lay on its anterior surface (Figure 3c). The anomalous muscle was mobilised and excised completely, after which haemostasis was achieved and the skin closed in layers.

The patient's ankle was splinted in a below-knee backslab for 10 days to allow adequate wound healing. He was thereafter not restricted and returned to cycling after 4 weeks. He reported no recurrence of paraesthesia after returning to pre-surgery activity level and was still symptom free at 1-year follow-up.

\section{Discussion and literature review}

The accessory soleus muscle presents as a posteromedial soft tissue mass in the lower leg. It may simulate a soft tissue tumour with a differential diagnosis that includes lipoma, ganglion, haemangioma, synovioma and sarcoma. ${ }^{3,4}$ It may also be a cause of recurrent tarsal tunnel syndrome, and failure of tarsal tunnel decompression has been shown to be due to the presence of an undiagnosed accessory soleus. ${ }^{5}$

The anatomical variants have been described by Sookur et al. ${ }^{6}$ This accessory muscle may originate from the anterior fascia of the soleus muscle; the posterior aspect of the head and upper shaft of the fibula; the soleal line of the tibia; and the middle third of the medial border of the tibia. It inserts on the Achilles tendon or on the superior or medial aspect of the calcaneus with either a muscular or tendinous insertion. ${ }^{7,8}$ It is usually enveloped within its own fascia and derives its neurovascular supply from branches of the posterior tibial artery and tibial nerve. ${ }^{8}$
Patients may present with muscular or neuropathic pain associated with paraesthesia and radiation into the posteromedial ankle and plantar aspect of the foot. This is commonly exacerbated by physical activity. Theories that may explain the origin of pain include a localised compartment syndrome caused by an increase in the size of the anomalous muscle during exercise, a compression neuropathy caused by the proximity of the accessory soleus to the tibial nerve or a claudication of the muscle due to a tenuous and insufficient blood supply from the posterior tibial artery during exercise. ${ }^{8}$ Partial tears and strains to the accessory muscle, as well as an association between an accessory soleus and Achilles tendinopathy have also been described. ${ }^{9}$

\section{Patients may present with muscular or neuropathic pain associated with paraesthesia and radiation into the posteromedial ankle and plantar aspect of the foot}

Diagnostic imaging begins with plain radiographs, which will rule out bony pathology and may demonstrate an increased opacity in the retrocalcaneal space (Kager's triangle) and a posterior soft tissue shadow. MRI should be considered essential in diagnosis and decision-making, to confirm the benign nature of the mass, describe in detail the anatomy of the anomalous muscle for surgical planning and rule out any of the differential diagnoses as described above. $^{10}$

Conservative management remains the first step in the treatment of a symptomatic accessory soleus in athletic and sedentary patients, and is effective in a large number of reported cases. These measures include activity modification, rest, elevation, the use of NSAIDs and physical therapy which includes massage, stretching and eccentric muscle training typically over a 12 -week period. ${ }^{10}$

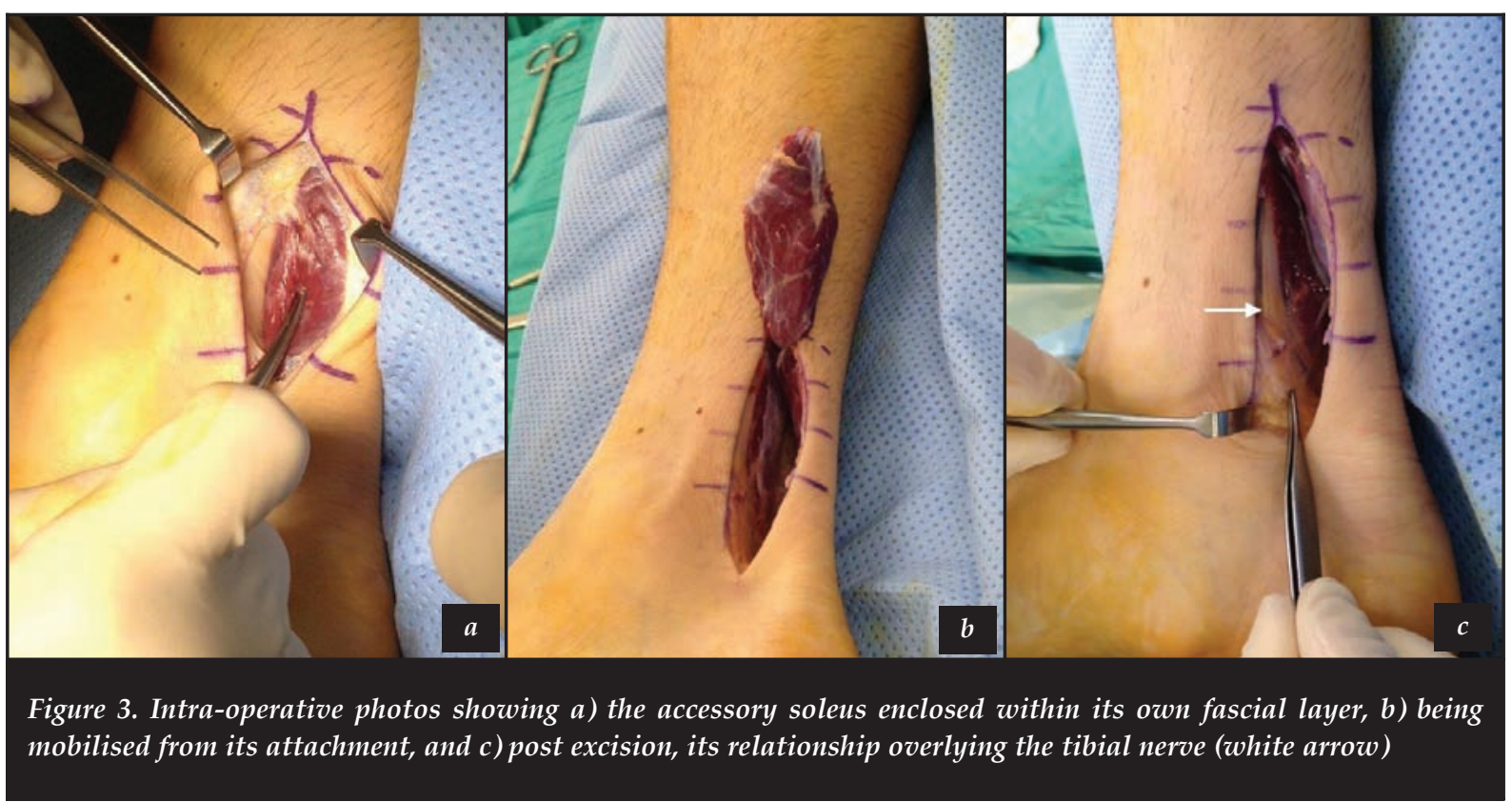


Surgery should be considered when conservative measures fail, especially in athletic patients. Surgical treatments previously reported include debulking of the muscle, fasciotomy, total excision and even ligation of the accessory muscle's blood supply. ${ }^{11}$ The largest case series of 21 patients by Kouvalchouk et al. ${ }^{12}$ suggested that complete resection is the most reliable treatment in symptomatic patients. However other smaller series have shown fasciotomy and excision to be equally effective. ${ }^{1,13}$ There does seem to be a trend in the literature towards complete excision of the accessory soleus in athletic patients and in general, fasciotomy can be considered for patients with a small accessory soleus or with low activity level and excision for patients with a large accessory muscle and those involved in high level sporting activities.

\section{Summary}

The accessory soleus muscle should be considered as a cause of compression neuropathy of the tibial nerve, especially in the presence of a posteromedial lower leg mass. Clinical examination and MRI scans form the basis of diagnosis. Treatment should include an attempt at conservative management; however, surgical intervention has shown good results with minimal complications.

The content of this article is the original work of the authors. No benefits of any form have been or are to be received from a commercial party related directly or indirectly to the subject of this article.

\section{References}

1. Brodie JT, Dormans JP, Gregg JR, et al. Accessory soleus muscle. A report of 4 cases and review of literature. Clin Orthop 1997;337:180-86.

2. Romanus B, Lindahl S, Stener B. Accessory soleus muscle: a clinical and radiological presentation of eleven cases. J Bone Joint Surg Am 1986;68:731-34.
3. Palaniappan M, Rajesh A, Rickett A, Kershaw CJ. Accessory soleus muscle: a case report and review of the literature. Pediatr. Radiol. 1999;29(8):610-12.

4. Dunn AW. Anomalous muscles simulating soft-tissue tumors in the lower extremities. Report of three cases. $J$ Bone Joint Surg Am.1965;47(7):1397-400.

5. DosRemedios ET, Jolly GP. The accessory soleus and recurrent tarsal tunnel syndrome: Case report of a new surgical approach. J. Foot Ankle Surg 2000;39(3):194-97.

6. Sookur PA, Naraghi AM, Bleakney RR, Jalan R, Chan O, White LM. Accessory muscles: anatomy, symptoms, and radio-logic evaluation. Radiographics 2008;28:481-99.

7. Lorentzon R, Wirell S. Anatomic variations of the accessory soleus muscle. Acta Radiol 1987;28:627-29.

8. Yu JS, Resnick O. MR imaging of the accessory soleus muscle appearance in six patients and a review of the Literature. Int Skeletal Soc. 1994;525-28.

9. Luck MD, Gordon AG, Blebea JS, Dalinka MK. High association between accessory soleus muscle and Achilles tendonopathy. Skeletal Radiol 2008;37(12):1129-33.

10. Rossi R, Bonasia DE, Tron A. Accessory soleus in the athletes: literature review and case report of a massive muscle in a soccer player. Knee Surg Sports Traumatol Arthrosc 2009;17:990-95.

11. Trosko JJ. Accessory soleus: a clinical perspective and report of three cases. J Foot Surg 1986;25:296-300.

12. Kouvalchouk JF, Lecocq J, Parier J, Fischer M. The accessory soleus muscle: a report of 21 cases and a review of the literature. Rev Chir Orthop Reparatrice Appar Mot 2005;91(3):232-38.

13. Chittaranjan BS, Babu NV, Abraham G. Accessory soleus muscle: a problem of awareness. Aust N Z J Surg 1994;64:503-505.

This article is also available online on the SAOA website (www.saoa.org.za) and the SciELO website (www.scielo.org.za). Follow the directions on the Contents page of this journal to access it. 